\title{
Genetic variation for seed yield in Caucasian clover
}

\author{
K.H. WIDDUP, T.L. KNIGHT and L.M. HUNT \\ AgResearch, PO Box 60, Lincoln, Canterbury
}

\section{Abstract}

The seed production potential of 34 lines of Caucasian clover (Trifolium ambiguum M.Bieb) representing a range of $2 \mathrm{x}$ (diploid), 4x (tetraploid) and 6x (hexaploid) material together with ecotypes from the Caucasus region were established in a trial at Lincoln, Canterbury $\left(43^{\circ} 38^{\prime} \mathrm{S}\right)$ in October 1993. Measurements were made from individual plants during summer 1994-95. The diploids were earliest to flower followed by the tetraploids and finally the hexaploids, which reached peak flowering in mid December. The hexaploids produced the most florets per inflorescence (115, 101, 96 from $6 x, 4 x, 2 x$ respectively), the most inflorescences per plant $(162,101,129$ from $6 \mathrm{x}$ $4 \mathrm{x}, 2 \mathrm{x})$ and the highest seed yield $(\mathrm{g})$ per plant $(26$, 9, 11 from $6 x, 4 x, 2 x)$. There was large variation for all the seed production components within the three ploidy levels. For example, the hexaploid cultivar Endura consisted of plants that varied from 25-510 inflorescences per plant. The seed yield components of plants were associated with active spring growth. There was evidence of wide spreading plants producing lower numbers of -inflorescences per $\mathrm{m}^{2}$-and-seed yield per-unit area: The hexaploid material produced the greatest potential seed yields $(1330,685,1000 \mathrm{~kg} / \mathrm{ha}$ from $6 \mathrm{x}, 4 \mathrm{x}, 2 \mathrm{x}$ respectively). There was a 5 -fold difference between the lowest-yielding $6 x$ cultivar, Prairie $(570 \mathrm{~kg} / \mathrm{ha})$, and the highest-yielding KZ2 $(2720 \mathrm{~kg} / \mathrm{ha})$, a selection from Monaro. Major gains are possible through selection but it is important to select for improved seed yield per plant (not just flowers) and to maintain a wide genetic base. Commercial crops yield approximately half that attained from research plots, which suggests a commercial yield of $900 \mathrm{~kg} / \mathrm{ha}$ is possible from Endura. This compares favourably with other legumes but requires development of crop management practices that ensure consistently high seed yields.

Keywords: Caucasian clover, genetic variation, Kura clover, seed components, seed yield, Trifolium ambiguum

\section{Introduction}

Caucasian clover is recognised as a legume with strong perenniality and potential for dry, low fertility environments in the hill and high country regions of the South Island (Lucas et al. 1981; Scott 1985; Woodman et $\boldsymbol{a l}$. 1992). The ability of Caucasian clover to extend into summer-dry, lowland regions and even into irrigated pastures is currently under evaluation (Mosset al. 1996; Widdup, unpubl. data). At present, the critical factor affecting the future uptake and acceptability of this new clover by farmers is the reliable production of quality seed. Current cultivars from Australia, such as Prairie and Monaro, have shown variable and poor seed yields and are not commercially available.

One way of improving seed production is to develop better genetic material and improved cultivars. Caucasian clover contains a ploidy series with chromosome numbers from $2 \mathrm{x}=16,4 \mathrm{x}=32$ and $6 \mathrm{x}=48$. Kannenberg $\&$ Elliot (1962) showed there was very large variation for flowering and seed yield among plants and ploidy levels, and suggested gains could be made through selection. Wrightsons Ltd recently developed KZ1 (released as cv. Endura) through two cycles of natural selection for better seed yield from hexaploid Monaro plants-(Michael-Norris ${ }^{-}$pers.comm). Further-selection from KZ1 for early rhizome production and later flowering has resulted in KZ2, KZ3 and KZ4.

The purpose of this study was to determine the critical plant components linked with seed production in Caucasian clover and to assess the extent of variation between and within the ploidy levels for these seed yield components.

\section{$M$ aterials and methods}

A range of caucasian clover material was established at AgResearch, Lincoln (latitude $43^{\circ} 38^{\prime} \mathrm{S}$ ) on a Templeton silt loam. The genetic material consisted of diploid, tetraploid and hexaploid cultivars and breeding lines (Table 1) which have been developed in Australia, USA and New Zealand. The KZ series of lines were selected from Monaro (6x) for improved seed yield by Wrightsons Ltd. The cool-season selection and lines with early- to late-flowering patterns were selected from Monaro by AgResearch. The seven ecotypes were part of a collection 
from the Caucasus region made by the late Dr Margot Forde.

The material was established in a randomised complete block trial with 3 replications. Each line within a replication was represented by 10 plants spaced $1 \mathrm{~m}$ apart in a row, resulting in $\mathbf{3 0}$ plants per line in the trial. Seedlings were established in trays in theglasshouse, inoculated with recommended Rhizobium strains for each ploidy level and transplanted to the field as lo-week-old plants in October 1993. These plants were left to establish with occasional grazing until October 1994, when the trial was closed to assess seed production. The trial site was moderately fertile $(\mathrm{pH}=5.6$, Olsen $\mathrm{P}=20)$ and received superphosphate (0-9-O-I 1) at $200 \mathrm{~kg} / \mathrm{ha}$ annually. The trial was irrigated 2 times during summer 1994-95, with $50 \mathrm{~mm}$ at each irrigation. Fertility and moisture conditions were good for legume plant growth.

Seed production potential was assessed on individual plants over summer 1994-95. A beehive was positioned $50 \mathrm{~m}$ from the edge of the trial in November 1994. Reproductive characters measured included rate of inflorescence appearance (counts at weekly intervals during November and December), final number of inflorescences and seed yield per plant. A sample of 5 flowers from each plant was dissected for number of florets per inflorescence and seeds per floret. Plant spread was measured as the most distant daughter plants arising from rhizomes, which enabled an estimate of inflorescences per $\mathrm{m}^{2}$ and seed yield per ha. Other plant growth characters measured were leaf diameter $(\mathrm{mm})$ and spring growth on a 0.9 visual scale. The diploid, tetraploid, hexaploid and ecotype lines were averaged within their groups for the components measured to give an overall effect of ploidy level.

\section{R esults}

The diploid material started flowering in late October, peaked early December but continued to initiate flowers from rhizome shoots (daughter plants) into February (Figure 1). The tetraploids had a similar curve but more confined. The hexaploids were last to begin flowering but showed a greater peak of flowers by mid December than the other ploidy levels. The hexaploids also continued to flower into February. The ecotypes had a flowering curve similar to that of the diploid and tetraploid material.
The diploid, tetraploid and ecotype material had smaller flowers with significantly fewer florets per inflorescence than the hexaploids (Table 2). The tetraploids and ecotypes had significantly fewer seeds per floret than the diploid and hexaploid material, which contained about 0.9 seed per floret (Table 2). The combined effect was that hexaploids had more seeds per inflorescence than the other ploidy levels. Tetraploids and ecotypes produced fewer inflorescences per plant than the diploids, which in turn had significantly fewer than the hexaploids. Seed yield per plant is a function of the number of inflorescences and the number of seeds per inflorescence. The result was that hexaploids produced significantly greater seed yield per plant than the other ploidy levels.

When plant spread was taken into account, the diploids, with their narrow plants, produced potentially more inflorescences per $\mathrm{m}^{2}$ than higher ploidy levels (Table 2). However, the highest potential seed yield of $1330 \mathrm{~kg} / \mathrm{ha}$ was from the hexaploid material. The seed yields of the diploids were not significantly different to that of the hexaploids, whereas the tetraploids and ecotypes had significantly poorer yields. The hexaploids produced larger leaves and the most active spring growth compared with lower ploidy levels, and this was associated with better seed yield per plant and total seed yield.

The hexaploid material was examined more closely to determine the extent of genetic variability of plant 
Figure I Rate of inflorescence appearance on the diploid, tetraploid, hexaploid and ccotype Caucasian clover populations.

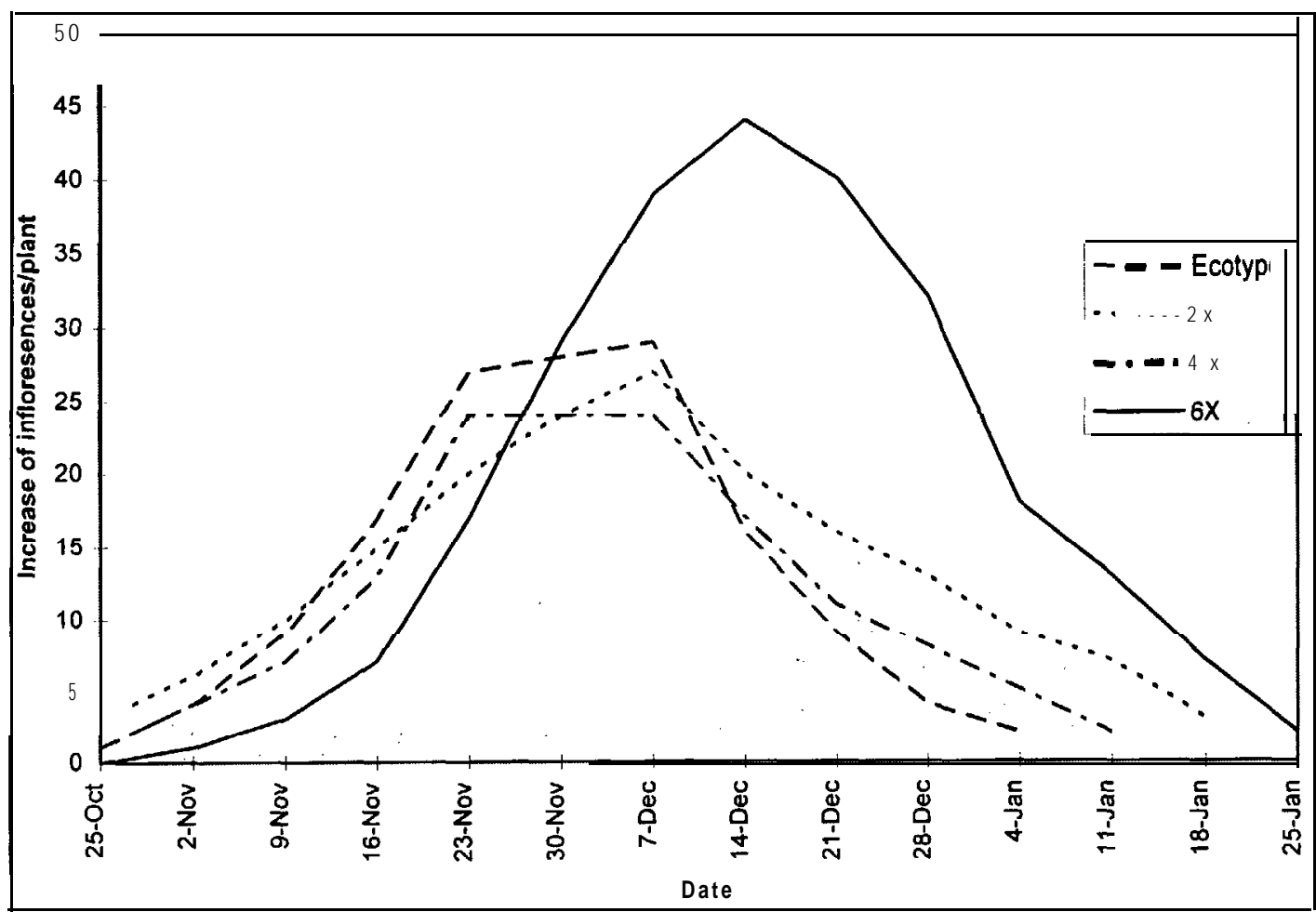

charaters that impact on seed production. Seven lines representative of the range of material from Australia, USA and New Zealand were chosen (Eigure 2). The KZ series of lines bad significantly greater seed yields per plant than Monaro, the cultiyar from which they were selected for improved seed yield (Figure 2a). The other USA and Australian cultivars were inferior to the $K Z$ series for seed vield per plant. The $K Z$ series showed more variation for this character than other material and offers wide scope for further selection. The USA line ARS 2678 and KZ2 - had -the most inflorescences_per_m $m^{2}$ (Figure 2b) and the least plant spread (Figure 2c). In contrast Prairie,: Monaro and KZ3 had fewer inflorescences per $\mathrm{m}^{2}$. but the greatest plant spread. Again, there was considerable variation for these two characters and the possibility for further gains through selection depending on the heritability of the two traits. The final potental seed yield $(\mathrm{kg} / \mathrm{ha}$ ) was greatest from the KZ series and ARS 2678 (Figure $2 \mathrm{~d}$ ), KZ2 producing the highest seed yields.
Table 2 Affect of ploidy level on the seed production components in Caucasian clover.

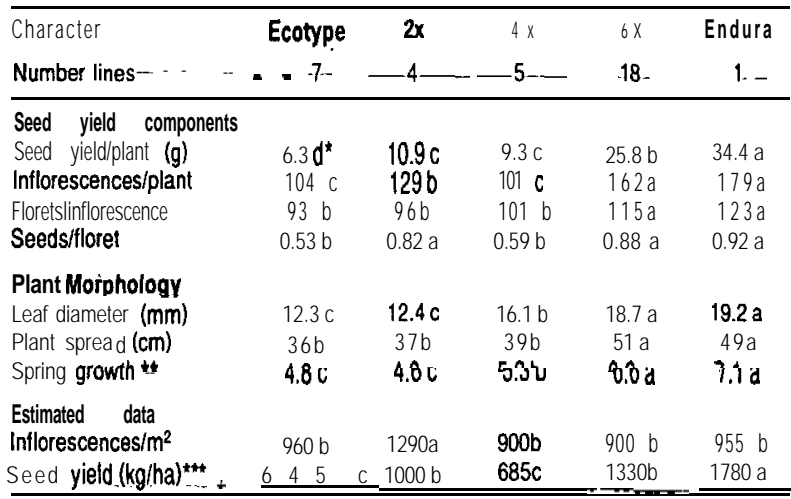

Diierent letters indicate significant differences for $\mathbf{P}<0.05$

n Sprino growth on 0-9 scale. $0=$ no growth, $9=$ excellent growth.

*** Potential yield of research plots are approximately twice those achieved from field crops.

\section{Discussion}

The progressively later flowering with increasing ploidy was similar to results from Kannenberg \& Elliott (1962) and Stewart (1979). In late October, stems appeared 
Figure 2 The mean $(\mathbf{D})$ and maximium $(\$)$ values for the seed yield components of seven hexaploid populations.

(a) Seed yield/plant (g)

(b) Number of inflorescences $/ \mathrm{m}^{2}$

(c) Rhizome spread (cm)

(d) Seed yield (kg/ha).

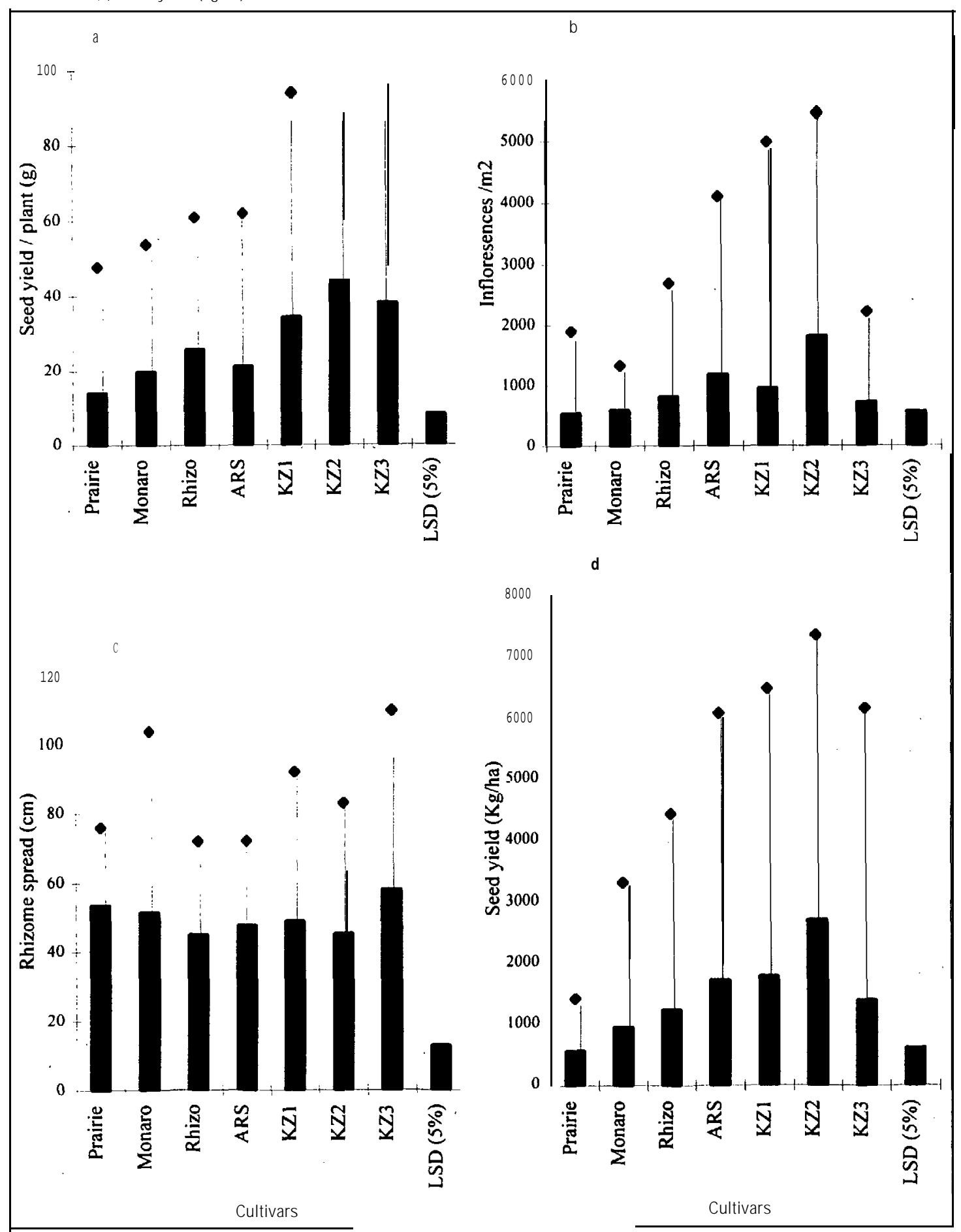


from the crown or rhizomes and continued to develop flower-bearing branches from each leaf axil, so that the youngest flowers were at the tip and the older flowers located further down the stem. This growth habit resulted in a wide span of flowering, with inflorescences appearing on stems into February. However, peak flowering had occurred by mid December. The ecotypes collected from the Armenian region had flowering patterns and flower structure similar to those of the diploids and tetraploids, but cytological examination would be required to verify their ploidy level. There is a lack of knowledge on the photoperiod and temperature effects on flower induction in Caucasian clover, although low temperature appears to be required for flower induction (Taylor 1994).

The hexaploids produced the largest inflorescences with more florets than other ploidy levels. Pollination was effective by honey bees, with the hexaploids and diploids producing approximately one seed per floret. Caucasian clover can develop two ovules per ovary in the floret (Gamtsemlidze 1995), which is similar to red clover (Trifolium pratense L.). Some hexaploid plants produced an average of 1.6 seeds per floret, indicating the possibility of selection for more seeds per inflorescence. The hexaploids also produced the most inflorescences per plant, and together with more seeds per inflorescence resulted in significantly greater seed yield per plant than lower ploidy levels. High seed yield per inflorescence and per plant was strongly associated with actively growing plants. Full development of each reproductive component depends on the partitioning of adequate resources, as has been shown with white clover (Clifford 1987). Seed yields from Caucasian clover appear to be maximised where plants have abundant space, nutients and moisture to fulfil their reproductive potential.

There was evidence of wide spreading plants producing fewer inflorescences per $\mathrm{m}^{2}$, with reduced total seed yield. Care should be taken in breeding programmes, when selecting plants for their ability to spread in a grass sward, not to penalise the associated seed production components. Optimium seed yield per ha will be achieved from cultivars with moderate -r rhizome development together .with appropriate-row spacing. Recent studies have shown $45 \mathrm{~cm}$ as the optimal spacing with Endura (Guy 1996). The hexaploid plants in this study averaged $50 \mathrm{~cm}$ in width after 18 months, which would have resulted in full canopy cover. Diploid and tetraploid plants averaged $35 \mathrm{~cm}$ in width, suggesting a $30 \mathrm{~cm}$ row spacing as more appropriate to maximise seed yield with lower ploidy cultivars.

There was considerable variation for seed yield between and within the hexaploid populations. Prairie had the lowest estimated yields $(570 \mathrm{~kg} / \mathrm{ha})$ whereas KZ2 had a potential yield of $2720 \mathrm{~kg} / \mathrm{ha}$, a S-fold advantage. Two cycles of selection for improved seed yield per plant in Monaro have doubled the seed yield to $1780 \mathrm{~kg} / \mathrm{ha}$ for Endura (KZ1). KZ2 represents another cycle of selection which provided a further $50 \%$ increase in seed yield. There is still sufficient variation in these lines to enable further selection gains. The major components on which to concentrate efforts are seed yield per plant and number of inflorescences per $\mathrm{m}^{2}$. However, selection for higher seed yields has not always been successful. A recurrent selection programme for improved flower numbers in Rhizo did increase flowers for the first season but seed yield was not improved (Taylor 1994). There was an associated decline in plant vigour, probably owing to inbreeding depression. This has not been the experience with the KZ series, where selection was for improved seed yield per plant (not just flowers), and a broad genetic base was maintained by allowing elite plants to open pollinate with the whole population.

A small group of lines was covered with animal exclusion cages in October 1995 to determine reproductive potential for the third season. Endura was typical of the lines tested, with a decline from 1000 to 250 inflorescences per $\mathrm{m}^{2}$ and from $34 \mathrm{~g}$ to $6 \mathrm{~g}$ seed per plant, a 5 -fold decrease, contrary to results from Dalyet al. (1993) where seed yields were maintained into a third season. Further research is required on the factors involved with producing multiple seed crops over a number of years.

Commercial crops yield approximately half the potential indicated from research plots owing to losses in harvesting and errors in extrapolating to larger areas, which would be equivalent to $500 \mathrm{~kg} / \mathrm{ha}$ from Monaro and $900 \mathrm{~kg} / \mathrm{ha}$ from Endura. Hexaploid Caucasian clover has potential to produce high seed yields which compare favourably with those of other legumes. The challenge now is to further develop the management requirements for a field crop to achieve consistently high crop yields.

\section{ACKNOWLEDGEMENTS}

Thanks to Peter Clifford and Mike Norris for genetic material-and discussions during the trial and Chris Pennell for technical help.

\section{REFERENCES}

Clifford, P.T.P. 1987. Producing high seed yields from high forage producing white clover cultivars.Journal of applied seed production 5: 1-9.

Daly, G.T.; Gurung, J.; Lucas, R.J. 1993. Stand age and closing date effects on seed yield of Caucasian and zigzag clover cultivars. Proceedings of the XVII International Grassland Congress: 1664-I 666. 
Gamtsemlidze, Z. 1995. Biological and Ecological studies of Trifolium ambiguum in Kazbegi area (central Caucasus). Reportfrom Institute of Botany of Georgian Academy of Sciences.

Guy, B.R. 1996. Caucasian (Kura) clover: Progress towards commercial seed production. Proceedings of the New Zealand Grassland Association 58: (these proceedings).

Kannenberg, L.W.; Elliott, F.C. 1962. Ploidy in Trifolium ambiguum M.Bieb. in relation to some morhological and physiological characters. Crop science 2: $378-381$.

Lucas, R.J.; White, J.G.H.; Daly, G.T.: Jarvis, P.; Meijer, G. 1980. Lotus, white clover and Caucasian clover oversowing, Mesopotamia Station, South Canterbury, Proceedings of the New Zealand Grassland Association 42: 142-151.

Moss, R.; Burton, R.; Allan, B.E. 1996. Productivity of Caucasian clover in irrigated pastures. Proceedings of the New Zealand GrasslandAssociation 58: (these proceedings).

Scott, D. 1985. Plant Introduction trials:genotypeenvironment analysis of plant introductions for the high country. New Zealandjournal of experimental agriculture 13: 117-1 27.

Stewart, A.V. 1979. Genotypic evaluation of Trifolium ambiguum. MSc thesis, Lincoln College, University of Canterbury.

Taylor, N.L.; Cornelius, P.L. 1994. Influence of recurrent selection for flowering on flowering and yields in Kura clover. Euphytica 72: 9-14.

Woodman, R.F.; Keoghan, J.M.; Allan, B.E. 1992. Pasture species for drought-prone lower slopes in the South Island high country. Proceedings of the New Zealand Grassland Association 54: 115-120. 